\title{
Seismic Characterization of Hypogenic Karst Systems Associated with Deep Hydrothermal Fluids in the Middle-Lower Ordovician Yingshan Formation of the Shunnan Area, Tarim Basin, NW China
}

\author{
Hongtao Zhu, Xiu Zhu, and Honghan Chen \\ Key Laboratory of Tectonics and Petroleum Resources, China University of Geosciences, Ministry of Education, Wuhan 430074, China \\ Correspondence should be addressed to Hongtao Zhu; htzhu@cug.edu.cn
}

Received 3 March 2017; Revised 11 May 2017; Accepted 27 July 2017; Published 13 September 2017

Academic Editor: Zhijun Jin

Copyright (C) 2017 Hongtao Zhu et al. This is an open access article distributed under the Creative Commons Attribution License, which permits unrestricted use, distribution, and reproduction in any medium, provided the original work is properly cited.

\begin{abstract}
Two fundamental forms of hypogenic karst systems (lateral stratiform hypogenic and cross-formational fault-vein hypogenic karst system) are distinguished mainly by differential effects of preexisting faults. In seismic cross sections, hypogenic karst systems are expressed as complex string-beads-like seismic reflections associated with faults. In this study, a new seismic characterization workflow was developed including seismic amplitude thresholding, fault interpretation, pickup, and merge display to enhance the description of the spatial distribution and coupling of hypogenic karst system and faults. The results suggest that the lateral stratiform hypogenic karst systems are predominantly developed at the top of the secondary faults, presenting an overall of "layered distribution and finger-like interaction" features. The cross-formational fault-vein hypogenic karst systems are developed around faults and characterized by dendritic distribution. Furthermore, we infer that the development pattern of hypogenic karst systems has been produced by the interplay of the faults, preexisting epigenic karst systems, and lateral carrier-beds, which together combine the complex hydrothermal migration pathways of fluids with the characteristics of vertical and horizontal combined pathways. In addition, some possible controlling factors (e.g., sequence stratigraphic boundaries, paleogeomorphology, and sedimentary facies) that can influence the development of these hypogenic karst systems have been discussed in detail.
\end{abstract}

\section{Introduction}

It has been well documented that there exists tremendous exploratory potential of the deep subsurface, which has recently drawn attention of petroleum geologists worldwide (e.g., [1-3]). One of the forming mechanisms of deeply buried carbonate reservoirs $(>4500 \mathrm{~m})$ is related to dissolution effects by fluids in the deep subsurface (e.g., $[4,5])$. The fluids here are not meteoric in origin but typically refer to hydrothermal fluids, which enter the relatively shallow subsurface from deep along the faults. Hypogenic karst systems influenced by deep hydrothermal fluids contribute to the formation of the quality deep carbonate reservoirs and have been found in the Yingshan Formation $(>6000 \mathrm{~m}$ ) of the Shunnan area, Tarim Basin, NW China. In addition, hydrothermal minerals (calcite, quartz, and tabular anhydrites) provide evidence that hypogenic karst systems affected by hydrothermal fluids are also found in the Yingshan Formation. Clearly understanding the characteristics of hypogenic karst systems developed in Yingshan Formation is therefore of significance to optimizing petroleum exploration and increasing reserves.

Hypogenic karst is a genic type of karst, regardless of the lithologies in which it develops [6,7]. Speleogenesis is often considered as the primary mechanism of the formation of karst because almost all essential attributes of karst owe their origin to speleogenesis [7]. Two fundamental types of speleogenesis, hypogene and epigene, are differentiated mainly by the distinct hydrodynamic characteristics of the respective groundwater flow systems: (1) stratiform confined aquifer systems or across-formational fracture-vein flow systems, of varying depths and degrees of confinement, and (2) hydrodynamically open, near-surface unconfined systems 

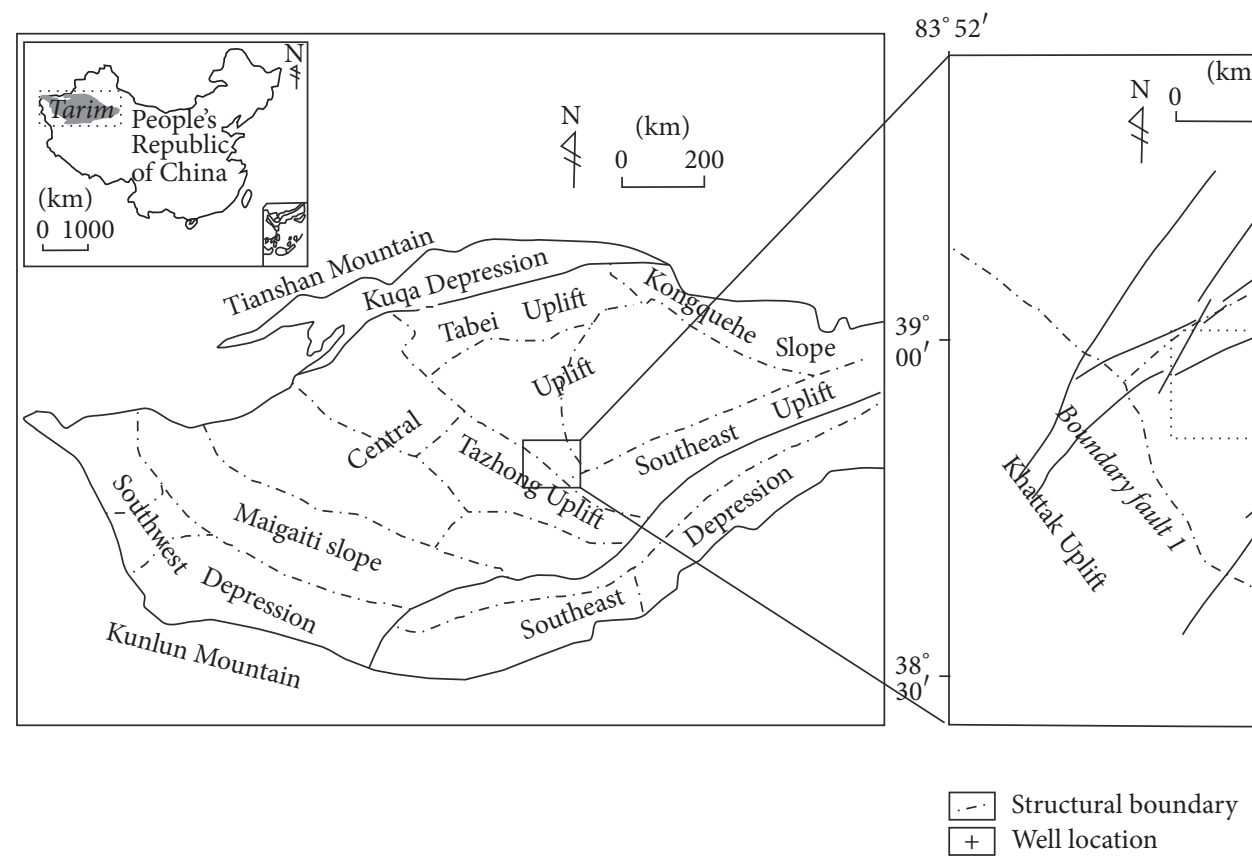

(a)

(b)

Figure 1: Location of the Shunnan area in the Central Tarim Basin, NW China. (a) Location of the Tarim Basin in China and the Tazhong uplift in Tarim Basin. (b) Main tectonic units of the Shunnan area.

[7]. Accordingly, the principal difference between hypogenic and epigenic karst systems lies in the modes (confined versus unconfined) and principal vectors (ascending versus descending) of fluid circulation and in the source of recharge to a given unit (recharge from depth versus recharge from the overlying or immediately adjacent surface) $[6,7]$.

There have been many case studies on carbonate karst over the past six decades, but they deal mainly with epigenic karst systems (e.g., [8-14]). The progress on the characterization of the hypogenic karst systems (e.g., [15-19]) predominantly focuses on the planar- or section-view delineations of lateral stratiform hypogenic karst system zones and relevant fault system zones individually. The "lateral stratiform hypogenic karst system zone" is used to denote the zone where fluids are directed transversely flow across layers and formation and in which fluids related to upwelling flows from the deep subsurface and upwards migrate along the faults. The relevant "fault system zone" in this paper not only denotes the migration pathways (faults) of ascending fluids that contribute to the formation of hypogenic karst system but also refers to the "cross-formational fault-vein hypogenic karst system," which is characterized by developing parallel around faults.

The Shunnan area is a three-level structural unit within the Tarim Basin, located at the downthrown side of the boundary fault I of the Tazhong Low uplift (Figure 1). It is bounded to the west by the Khattak Uplift, north by the Shuntuoguole Low uplift, south by the Guchengxu Low uplift, and east by the Mangar sag (Figure 1). In recent years, hydrothermal minerals (calcite and quartz in veins and tabular anhydrites) at depths $(>6000 \mathrm{~m})$ and distinctive seismic reflections that are expressed by a series of individual stringbeads lateral spreading have been found in the Shunnan area. These provide the potential conditions to characterize the distribution of the hypogenic karst systems.

The aim of this paper is to understand the spatial distribution and controlling factors of hypogenic karst development and develop a model of the karst systems in the MiddleLower Ordovician Yingshan Formation of Shunnan area, Tarim Basin, NW China. In this paper, the hypogenic karst systems and faults were first distinguished on the basis of an integrated approach of seismic data with available conventional cores, wells, and a scanning electron microscope analysis, and then a new seismic characterization workflow was developed, including seismic amplitude thresholding, fault interpretation, pickup, and merge display, to enhance the description of the spatial distribution and coupled hypogenic karst systems and faults. The proposed workflow will provide new insight into 3D seismic characterization of the hypogenic karst systems and can be used extensively in hypogenicrelated karst basins around the world.

\section{Geological Setting}

The Tarim Basin in western China (Figure 1) is a composite basin with a number of uplifts and depressions that developed as a result of a long and complicated tectonic history (e.g., [20-26]). It is located between the Tianshan Mountain and Kunlun mountains, occupying an area of $56 \times 10^{4} \mathrm{~km}^{2}$. The basin's east-west length is $1400 \mathrm{~km}$ while the maximum width reached $520 \mathrm{~km}$ with the altitude ranges between $800 \mathrm{~m}$ and $1300 \mathrm{~m}$. Collectively, the development of the basin's 

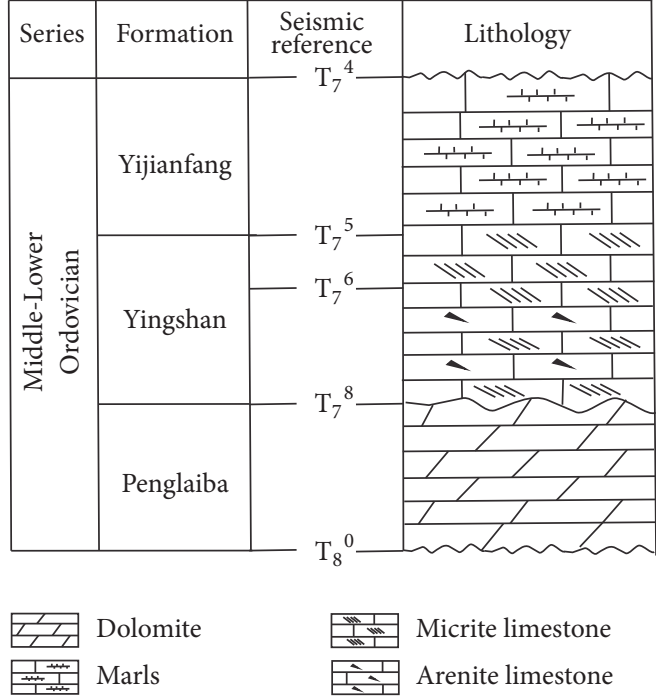

FIGURE 2: Generalized stratigraphic column of the Middle-Lower Ordovician of the Tarim Basin, showing lithology and seismic reference. The study interval is the Yingshan Formation.

current configuration and the geometry of tectonic elements are controlled mainly by multiple tectonic activities. The Tarim Basin is mainly divided into three uplifts and four depressions. From the north to the south, there are the Kuqa Depression, Tabei Uplift, Northern Depression, Central Uplift, Southwest Depression, Southeast Uplift, and Southeast Depression (e.g., [27-29]; Figure 1(a)).

The Tazhong Low uplift is located in the middle part of the Central Uplift in the Tarim Basin, covering an area of 2.9 $\times 10^{4} \mathrm{~km}^{2}$, and the terrain dips to northwest, generally like a bird foot or a broom (e.g., [29]; Figure 1(a)). The Middle Ordovician in the Tazhong area is subdivided into Yingjianfang and Yingshan Formations. The Lower Ordovician is subdivided into Yingshan and Penglaiba Formations. After the deposition of Lower Ordovician Penglaiba Formation, Tazhong area, subjected to compression, started to uplift.

The study area (Figure 1(b)) is a three-level structural unit, located at downthrown side of the boundary fault I of Tazhong Low uplift within Tarim Basin. It adjoins Khattak Uplift bounded by the boundary fault I on the western side; to the north, it is adjacent to the Shuntuoguole Low uplift. The gentle slope connects Guchengxu Low uplift to the south and Mangar sag to the east, respectively. The lower part of the Yingshan Formation was subjected to long-term exposure, forming intensive epigenic karst systems. To the contrary, the upper part of the Yingshan Formation did not experience exposure after deposition, and a large amount of hypogenic karst systems was found in the upper part of the Yingshan Formation. Seismic references $\mathrm{T}_{8}{ }^{0}$ and $\mathrm{T}_{7}{ }^{4}$ are the base and top of the Middle-Lower Ordovician, $\mathrm{T}_{7}{ }^{8}$ and $\mathrm{T}_{7}{ }^{5}$ are the base and top of the Middle-Lower Ordovician Yingshan Formation, and $\mathrm{T}_{7}{ }^{6}$ is the interface between the upper and lower Yingshan Formation. Those seismic references are shown in Figure 2.
The hypogenic karst systems are defined as the formation of caves by water that recharges the soluble formation from below, driven by hydrostatic pressure or other sources of energy and independent of the recharge from the overlying or immediately adjacent surface (e.g., [15]). It has been proved that carbonates may produce a series of geological and geochemical changes in the hydrothermal process and these changes may be reflected by mineralogy and geochemistry [30]. The hydrothermal fluids often contain some acid gases such as $\mathrm{CO}_{2}$ and $\mathrm{H}_{2} \mathrm{~S}$ [31], dissolve the original carbonates by the water-rock reaction, and form the hydrothermally associated minerals such as the fluorite, chlorite, sphalerite, and barite and even the hydrothermal mineral association [32]. Hydrothermal processes commonly form the associated minerals such as calcite, quartz, and tabular anhydrite in well SN4 (Figure 3). Present temperature is the highest temperature in the geological buried process of the Yingshan Formation [33], and geothermal gradient of the Shunnan area is 2.0 2.3 ${ }^{\circ} \mathrm{C} / 100 \mathrm{~m}[34,35]$. Therefore, the highest temperature in well SN4 of the Yingshan Formation is about $153 \sim 173^{\circ} \mathrm{C}$. The homogenization temperature of the original inclusion represents the temperature of the hydrothermal fluid [30]. The main homogenization temperatures of primary fluid inclusions in calcite and quartz are higher than the highest temperature of about $25^{\circ} \mathrm{C}$ in well SN4 [33], so the calcite and quartz must have been formed in high-temperature condition which may be mainly caused by hydrothermal fluids from the deep subsurface.

\section{Seismic Facies Variations between Epigenic and Hypogenic Karst Systems}

Classic seismic facies are groups of the characteristics of seismic reflections which differ from those of adjacent areas (e.g., [36]). Paleokarst seismic facies are extremely complex. Previously published studies provide valuable insights into seismic evidence of paleokarst facies (e.g., [23, 24, 37, 38]). Key seismic parameters include reflection amplitude, continuity of seismic events, apparent frequency, external form, and internal reflection configuration. The variations are utilized to infer the underlying geology (e.g., [23, 24, 39]). In this paper, two typical seismic facies referred to as the individual string-beads-like and complex string-beads-like are identified to describe the seismic reflections of epigenic and hypogenic karst systems, respectively, in the MiddleLower Ordovician Yingshan Formation. Detailed differences between both string-beads-like individuals and complexes are expounded in the following.

3.1. Seismic Facies of Epigenic Karst Systems. As noted in Klimchouk [7], epigene karstification occurs in the nearsurface conditions and is directly linked with recharge from the immediately overlying or adjacent surface. The individual string-beads-like seismic reflection has been interpreted as the evidences of "epigenic karst system" in the Tarim Basin in the published papers, which is always linked with the terms "unconformities, weathering crusts, exposure, etc." (Guo et al. 2012; Chen et al. 2014) [40, 41]. These terms are further related to the epigenic karst system development. Guo et al. 

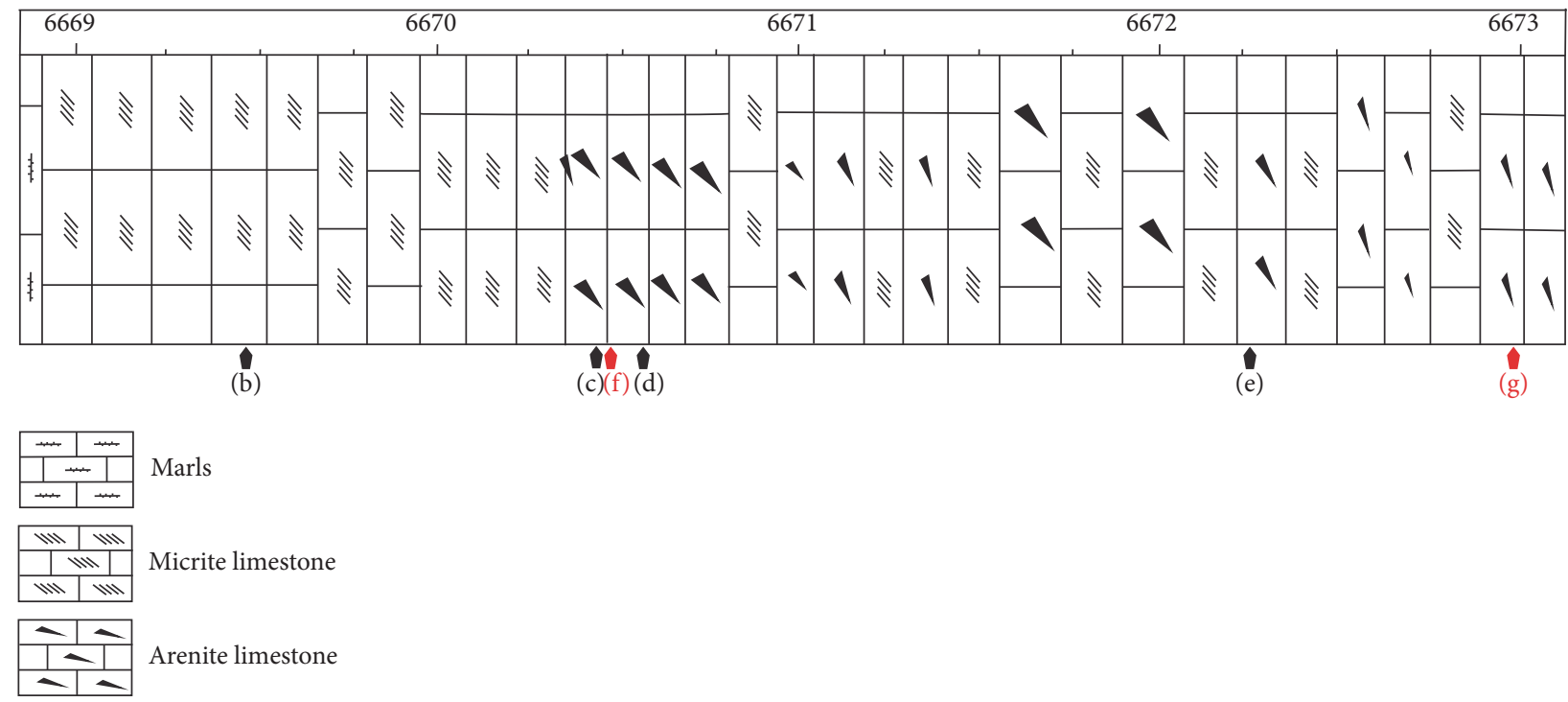

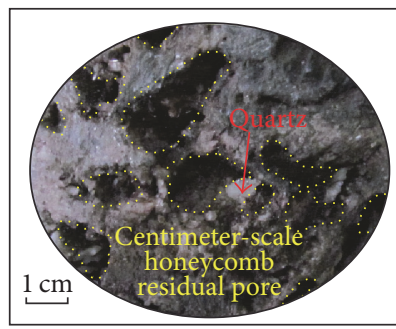

(b)

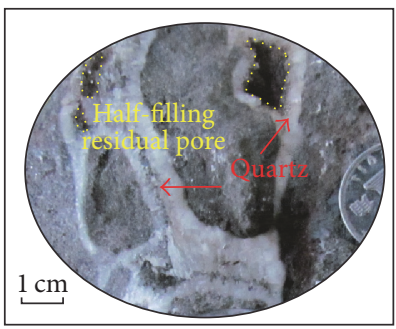

(c)

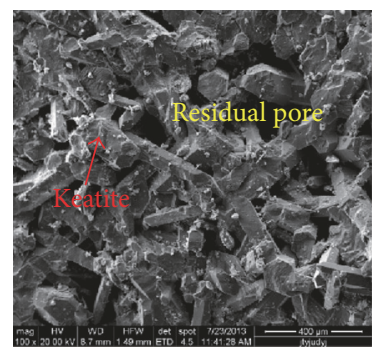

(f)

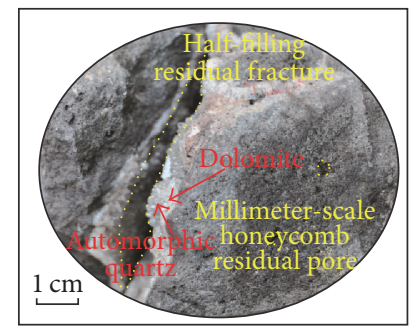

(d)

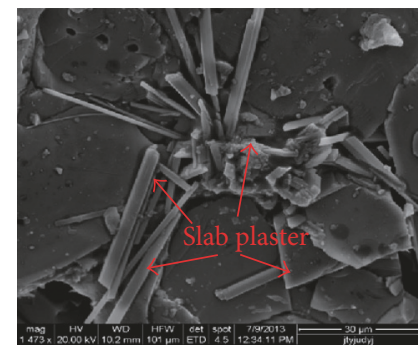

(g)

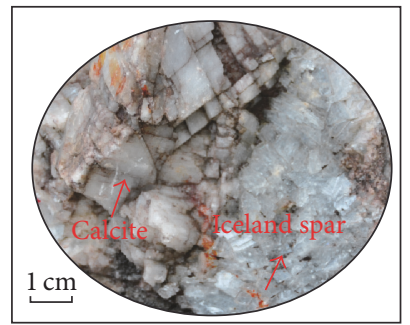

(e)

FIGURE 3: Petrologic characteristics of the Yingshan Formation determined from well SN4. (a) Lithology of well SN4 from 6668.3 to $6673.5 \mathrm{~m}$. (b) Centimeter-scale honeycomb residual pores, $6669.47 \mathrm{~m}$. (c) Half-filling residual pores along the fractures, $6670.44 \mathrm{~m}$. (d) Half-filling residual pores along the fracture and millimeter-scale honeycomb residual pores, $6670.57 \mathrm{~m}$. (f) Quartz in vein, $6670.48 \mathrm{~m}$. (e) Iceland spar (calcite), $6672.25 \mathrm{~m}$. (g) Tabular anhydrite, $6672.98 \mathrm{~m}$.

(2012) pointed out the individual string-beads-like seismic reflection in Yingshan Formation is attributed to weathering karst (epigenic karst). Chen et al. (2014) demonstrated the individual string-beads-like seismic reflection (strong or weak amplitude) is attributed to "epigenic karst system" on the basis of analysis of conventional cores, wells, and loggings in Yingshan Formation, Tarim Basin. In this paper, the author thought the development of karst system in Yingshan Formation is linked with the exposure environment and related to meteoric fluids. Gao et al. [40] demonstrated that the individual string-beads-like seismic reflection in the
Tazhong area is linked with the exposure environment. In this paper, the moldic and dissolution pores in well Shun2 (at depth of $6879.5 \mathrm{~m}$ ) are formed in the meteoric fresh water environment as a result of the repeated exposure of the carbonate platform. In addition, fibrous calcite cementation in well Shun6 (at the depth of $6646.9 \mathrm{~m}$ ) is also the indicator of the meteoric fresh water environment.

In the study area, many high-amplitude, low-continuous, individual string-beads-like seismic reflections were recognized in the lower part of the Yingshan Formation in the seismic cross sections (Figures 4(a) and 4(b)). These seismic 

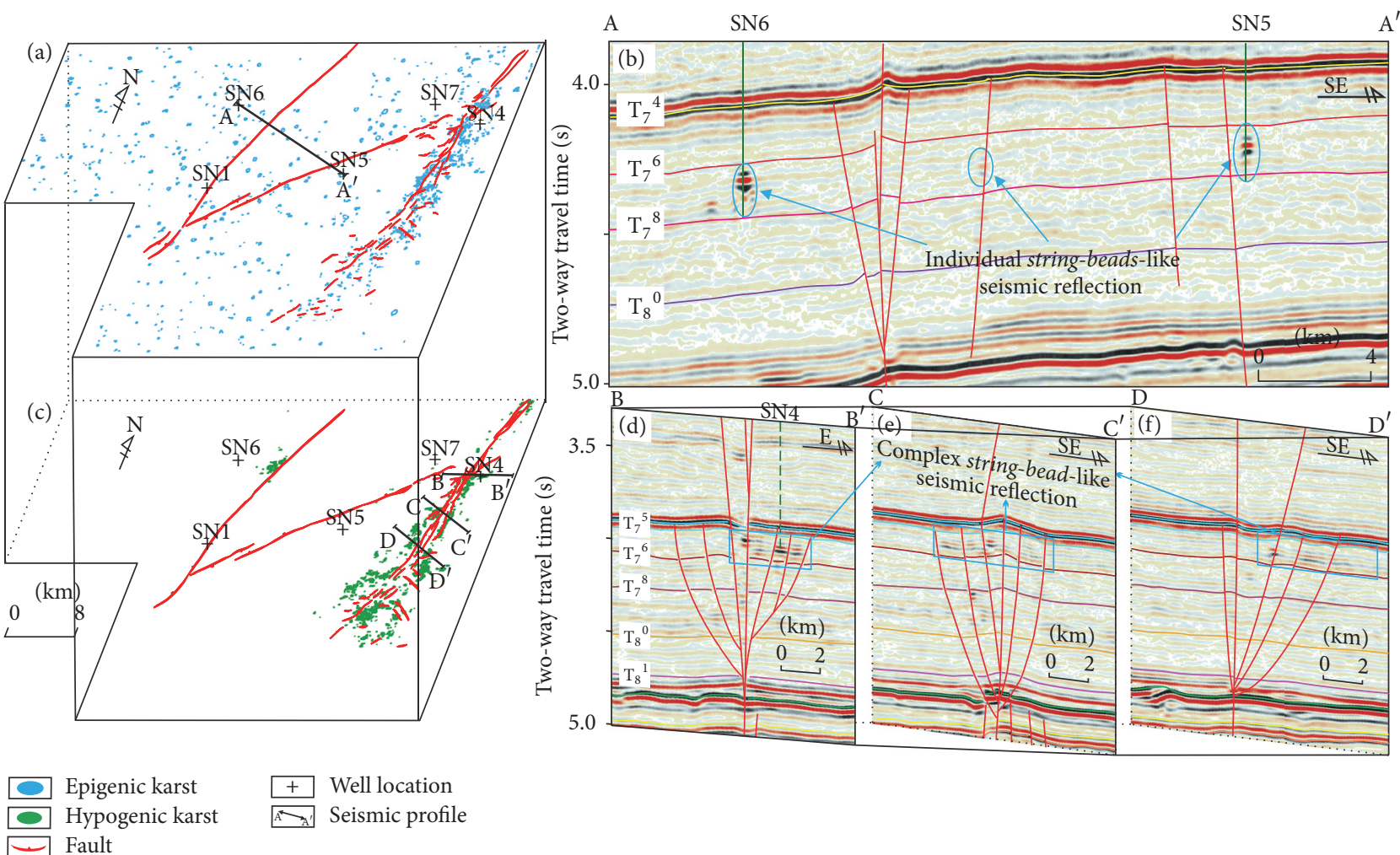

Figure 4: Seismic facies of epigenic karst systems and hypogenic karst systems of the Yingshan Formation in the study area. (a) Seismic attribute RMS (root mean square) map of the lower part of the Yingshan Formation. (b) Epigenic karst systems marked by the blue oval line across wells SN6 and SN5 seismic section, showing the typical individual string-beads-like seismic reflections. (c) Seismic attribute RMS (root mean square) map of the upper part of the Yingshan Formation. (d) Complex string-beads-like seismic reflections of hypogenic karst systems across well SN4 seismic section, developed associated with the faults. (e) and (f) Other seismic section showing complex string-beads-like seismic reflections of hypogenic karst systems, developed associated with the faults. The blue color indicates epigenic karst systems, distributed widely in the entire study area with the isolated punctate distributions; the green color indicates hypogenic karst systems, showing belt-shaped distributions along the SN4 fault zone.

reflections are characterized by multiple strong amplitudes with vertical build-ups and worm-like short-axis appearances, forming near-vertical columns, referred to as stringbeads. [41]. They predominantly reflect the distribution of the epigenic karst systems. Apart from the individual stringbeads-like seismic reflections, the strata are characterized by continuous parallel or subparallel seismic reflections (Figure 4(a); see [42]).

The seismic amplitude attribute (root mean square-RMS) map indicates that the isolated punctate anomalies caused by the individual string-beads-like seismic reflections of epigenic karst systems are widely distributed across the entire study area. This reveals that the epigenic karst systems are well developed in the lower part of the Yingshan Formation of the study area (Figure 4(a)).

\subsection{Seismic Facies of Hypogenic Karst Systems. A set of} hypogenic karst systems (lateral stratiform hypogenic and cross-formational fault-vein hypogenic karst systems) was recognized in the Upper Yingshan Formation of well SN4 area and the cross-well seismic sections. Differing with parallel or subparallel seismic reflections of the strata and individual string-beads-like seismic reflections of the epigenic karst systems, seismic reflections of hypogenic karst systems are usually composed of a series of individual string-beads, defined as a string-beads complex (Figures 4(c), 4(d), 4(e), and $4(\mathrm{f})$ ). Furthermore, compared with the isolated distribution of epigenic karst system in planar view, the string-beads complex of hypogenic karst systems is belt-shaped distributed along the faults in the planar view and the section view: (1) lateral stratiform hypogenic karst systems are well developed at the top of the secondary faults, and cross-formational faultvein hypogenic karst systems are developed around the faults through the seismic cross sections (Figures 4(d), 4(e), and 4(f)); (2) lateral stratiform hypogenic and cross-formational fault-vein hypogenic karst systems are well developed along the SN4 fault zone in the seismic attribute RMS map, showing the characteristics of a belt-shaped distribution and stringbeads complexes with distinctive strong amplitude anomalies (Figure 4(c)).

\section{3D Seismic Characterization of Hypogenic Karst Systems}

Investigations of hypogenic karst systems predominantly focus on the section- or planar-view delineation of a lateral 


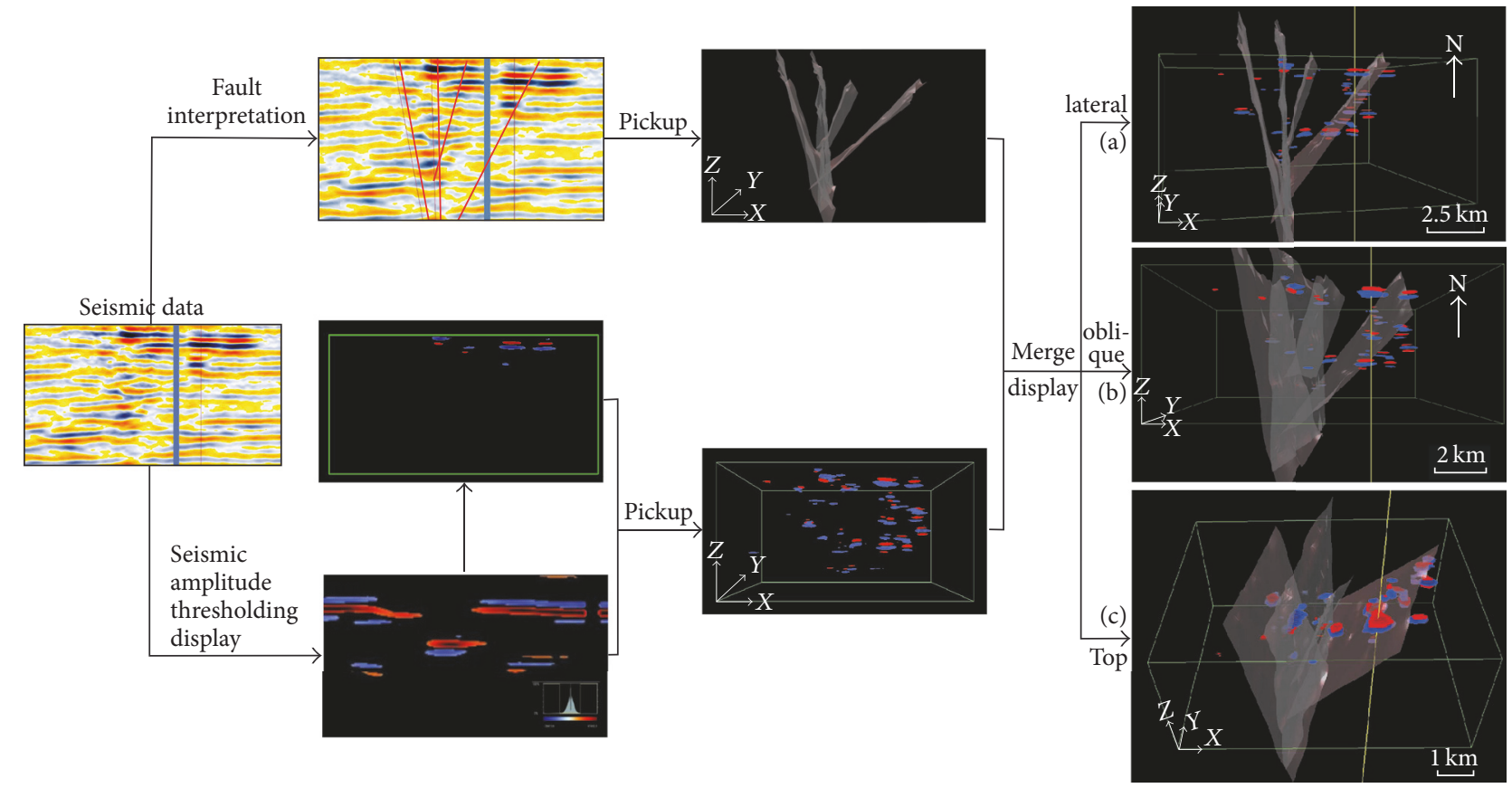

FIGURE 5: A new 3D seismic characterization workflow for hypogenic karst systems, including seismic amplitude thresholding, fault interpretation, pickup, and merge displays; 3D view of hypogenic karst systems in the study area ((a), (b), and (c)). (a) Coupling relationships between faults (multilevel faults) and hypogenic karst systems. (b) and (c) showing the lateral, oblique, and top distributions of hypogenic karst systems, respectively. Red and blue color represent hypogenic karst systems.

stratiform hypogenic karst system and the relevant fault system zone individually (e.g., [38, 43-47]).

Recently acquired 3D seismic data, covering the entire study area, make it possible to investigate the seismic facies and distributions of hypogenic karst systems [23, 24]. A new seismic characterization workflow has been developed in this study, including seismic amplitude thresholding, fault interpretation, pickup, and merge display to conduct a joint investigation of the spatial distribution and coupling of the lateral stratiform hypogenic karst system and relevant fault system zones (Figure 5). The relevant fault system zones are used in this paper to denote the migration pathways (relevant faults) of hydrothermal fluids and the cross-formational faultvein hypogenic karst systems around faults.

The workflow includes the following steps (Figure 5):

(1) Carry out the logging and seismic facies analysis based on 3D seismic data and drilling data, taking into account detailed comparisons of well-to-seismic ties, and then conclude with the characteristics of lateral stratiform hypogenic karst systems and their relevant fault system zone by analyzing seismic facies across different seismic lines.

(2) Characterize the hypogenic karst systems (lateral stratiform hypogenic and cross-formational faultvein hypogenic karst systems) on the basis of the attributes of strong seismic amplitude and high continuity: (a) Firstly, picking the overall attributes of the root mean square to determine the seismic amplitude classification standards and then defining the seismic amplitude distribution ranges of the hypogenic karst system, especially, the minimal seismic amplitude value is required.

(b) Secondly, display the part of the amplitude that is higher than the minimum amplitude value through seismic amplitude thresholding and strong amplitude pickup.

(c) Finally, characterize the spatial distribution of hypogenic karst system according to the above results.

(3) Display the spatial distribution of relevant faults through fault interpretation, pickup, and thresholding display.

(4) Merge displays lateral stratiform hypogenic karst systems and fault system zones.

\section{Characterization Results of Hypogenic Karst Systems}

Applying the proposed new seismic characterization workflow, a series of the spatial configuration diagrams show hypogenic karst systems and relevant faults, further analyzing their coupling relationship from different perspectives (Figures $5(\mathrm{a}), 5(\mathrm{~b})$, and $5(\mathrm{c}))$. 
Hypogenic karst systems constituted lateral stratiform hypogenic karst system and cross-formational fault-vein hypogenic karst system [7, 48]. Deep fluids upwards flowed along the faults and at the same time transversely migrated along the soluble formation and lateral stratiform hypogenic karst system is thus formed. Lateral stratiform hypogenic karst systems are predominantly characterized by an overall view of "horizontal layered distribution with certain lateral continuity" (Figure 5(a)). With the accumulation of fluids, lateral stratiform hypogenic karst systems are integrated and cut-through, making the layered characteristic apparent (Figures 5(a), 5(b), and 5(c)). It is shown in Figure 5(c) that lateral stratiform hypogenic karst systems formed in different locations at the top of the same faults generally exhibit the obvious amplitude abnormities. Seismic amplitudes decrease gradually away from faults or top downwards of faults, revealing the karstified range and intension decreasing gradually downwards in the lateral stratiform hypogenic system zones. Cross-formational fault-vein hypogenic karst system is usually formed around the faults; that is, the fault systems zone is cross-formational fault-vein hypogenic karst development zone.

The importance of faults in hypogenic karst system is reflected in two aspects. On the one hand, faults are vertical migration pathways of hydrothermal fluids, which are important for upwelling cross-communication between shallow and deep subsurface and further for lateral stratiform hypogenic karst system development. Because fluids in fault systems encounter the lateral carrier-beds (the unconformities, weathering crusts, and preexisting epigenic karst systems), fluids occur in lateral selective dissolution due to the high permeability of lateral carrier-beds, and the lateral stratiform hypogenic karst systems are developed (Figure 5(a)). On the other hand, fault zones are also cross-formational faultvein hypogenic karst development zones where ascending flows cross soluble and insoluble rocks. Accordingly, crossformational fault-vein hypogenic karst systems are developed around faults by the dissolution effects of fluids on massive rocks $[6,7]$. In addition, the faults comprised the primary faults and secondary faults with different characteristics. Primary faults are much rougher and their cross sections often exhibit the circular or elliptic physical characteristics. Conversely, the secondary faults are developed in three directions, vertical, horizontal, and bending and divergence in multiple directions, and their shape sizes have distinct differences, small to large (Figure 5(b)).

\section{Development Pattern of Hypogenic Karst Systems}

Based on the detailed characterization of hypogenic karst systems in the study area, the development pattern of hypogenic karst systems is proposed, where deep hydrothermal fluids migrated vertically through primary and secondary faults and flowed laterally through lateral carrier-beds (including unconformities, weathering crusts, the preexisting epigenic karst system, porous, or vuggy layers). The pattern shows that the hypogenic karst system has overall "vertical and horizontal combination, dendritic distribution, layered distribution, and finger-like interaction" features (Figure 6).

The vertical faults formed by primary and secondary faults have a positive effect on the development of hypogenic karst systems. The deep hydrothermal fluids flowed upwards along the multilevel faults, presenting "dendritic distribution" features. Subsequently, fluids migrated along the lateral carrier-beds horizontally, presenting "layered distribution" characteristics. The strata were subjected to selective dissolution in the course of the lateral migration, presenting typical "finger-like interaction" characteristics. Faults and lateral carrier-beds together formed a "vertical and horizontal combination" of hydrothermal migration pathways. Hypogenic karst systems have an overall "dendritic distribution, layered distribution, and finger-like interaction" features (Figure 6).

"Dendritic distribution" means that the hypogenic karst system is characterized by a multiple-level "dendritic" morphology. Primary faults are the "trunks" of vertical channels and secondary faults are "branches" accompanied by the diffusion of the hydrothermal fluids. In addition, the dissolved pores, karst cave, and dolomite reservoirs are further branches developed at the top of the secondary faults (Figure 6).

Hydrothermal fluids migrated upwards along the secondary faults, forming an intensive dissolution area. Then, hydrothermal fluids migrate horizontally along the lateral carriers, forming the "layered distribution" of dissolved pores systems. In addition, the dissolved pore systems formed by different secondary faults were fused and penetrated, making the "layered distribution" apparent. At the same time, when the hydrothermal fluids converged on the top of the secondary faults, selective dissolution gave priority to soluble sparry calcarenite compared with micrite. Altered soluble sparry calcarenite and unaltered micrite presented the characteristics of interbedding and alternative occurrence. More specifically, the strata consisted of altered sparry calcarenite accompanied by unaltered micrite interbed.

In summary, hypogenic karst systems can be interpreted as a tree-like cave system with an erect trunk in the bottom, bending in multiple directions upwards and changing into horizontal at the top, showing overall "vertical and horizontal combination, dendritic distribution, layered distribution, and finger-like interaction" features (Figure 6).

\section{Controlling Factors for Hypogenic Karst Systems}

The main controlling factors of the Ordovician karst systems are uplift, unconformity, fault systems, rock physical properties, and sedimentary facies $[13,26]$. In order to illustrate the spatial distributions, this paper will present the controlling factors of the hypogenic karst system through the analysis of fault systems, sequence stratigraphic boundaries, preexisting epigenic karst systems, paleogeomorphology, and sedimentary facies.

7.1. Relationships between Fault Systems and Hypogenic Karst Systems. Based on the distinct seismic reflections between 


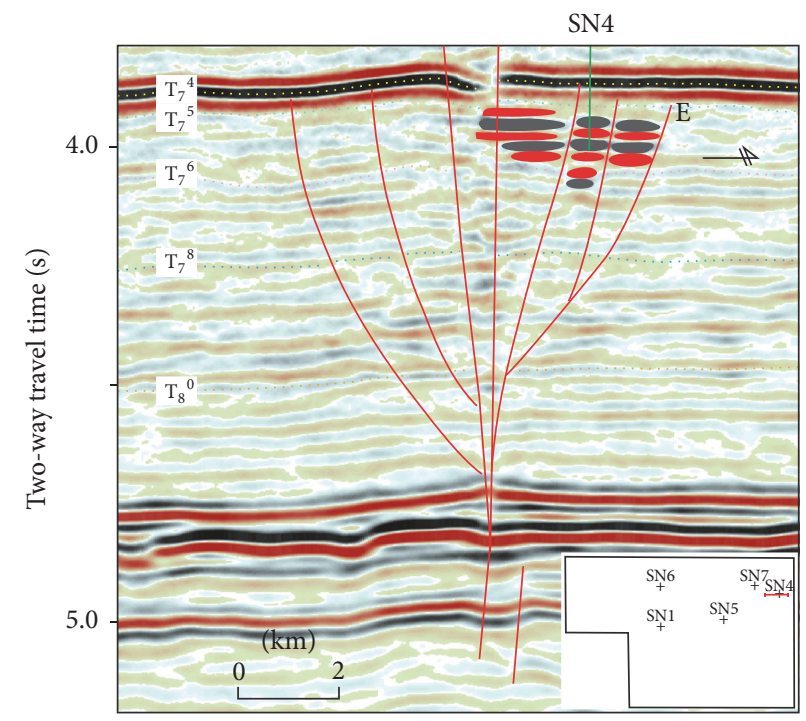

(a)
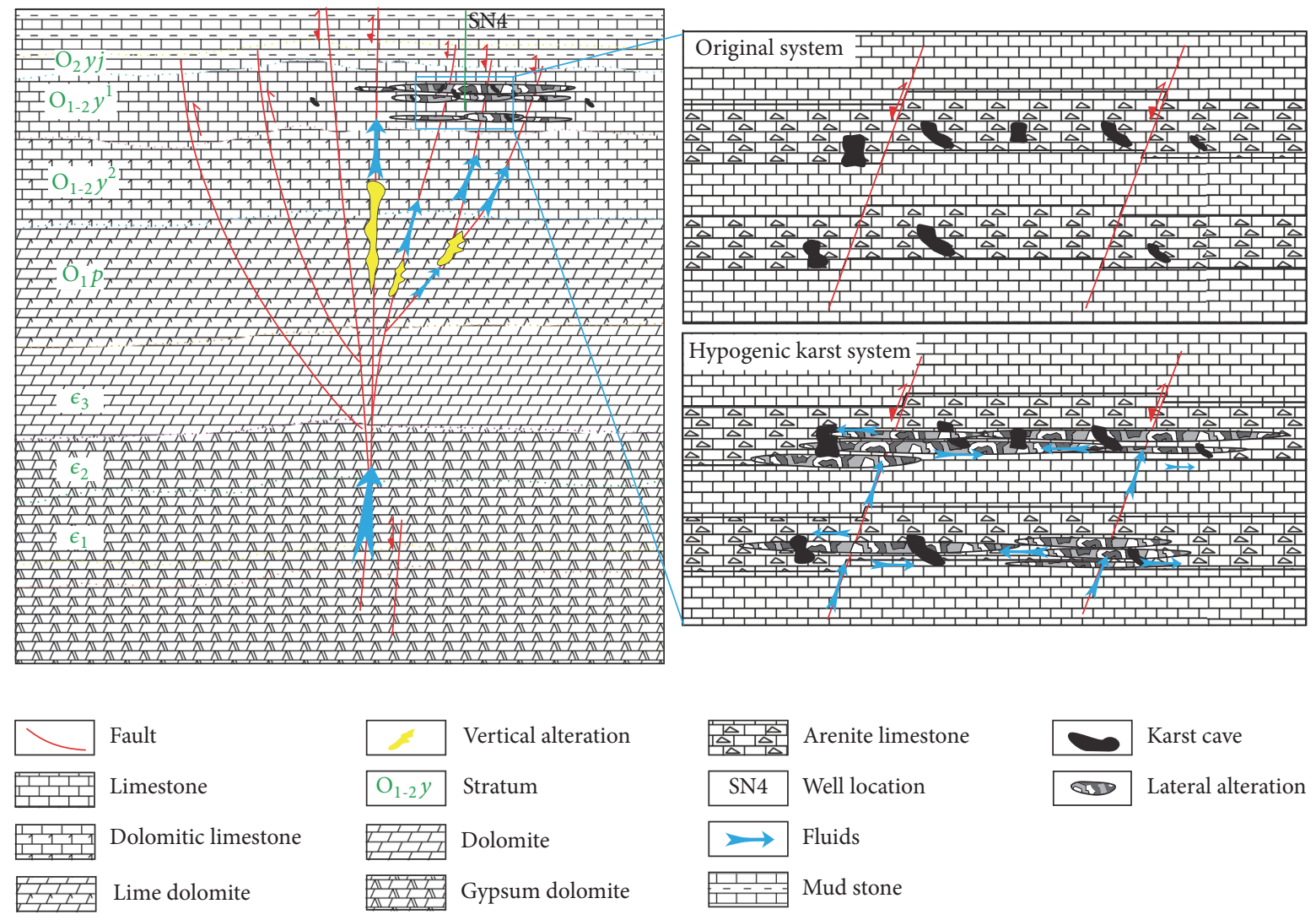

\begin{tabular}{|c|c|}
\hline$F$ & Vertical alteration \\
\hline $\mathrm{O}_{1-2} \mathrm{y}$ & Stratum \\
\hline 兵, & Dolomite \\
\hline $\begin{array}{lll}1 \\
11\end{array}$ & Gypsun \\
\hline
\end{tabular}
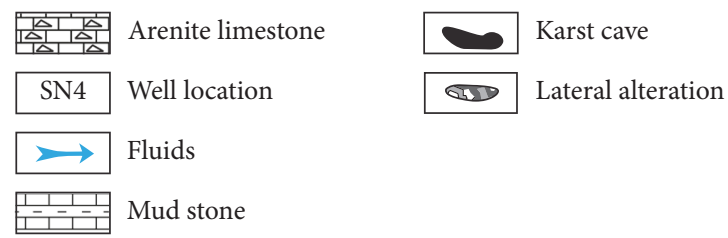

(b)

Figure 6: Development pattern of hypogenic karst systems of the study area. (a) Seismic dip section $\mathrm{DD}^{\prime}$ showing complex stringbeads-like seismic reflections of hypogenic karst systems in the Yingshan Formation. (b) Hydrothermal fluids pathways derived from the deep subsurface, showing vertical pathways (primary-secondary faults) and lateral carrier-beds (preexisting epigenic karst systems, unconformities, soluble layers, etc.). Accumulations of hydrothermal fluids make it possible for the scattered lateral carrier-beds to communicate with one another and formed hypogenic karst systems with such features as dendritic distribution, layered distribution, and finger-like interaction. 
the karst systems (low continuity and strong seismic amplitude) and surrounding rocks (high continuity and weak seismic amplitude), the planar distributions of epigenic and hypogenic karst systems in the Yingshan Formation were shown in Figures 4(a) and 4(c) by using the seismic amplitude attribute (RMS, root mean square).

The seismic attribute RMS map shows that isolated punctate anomalies are widely distributed across the entire study area, as recognition indicators of epigenic karst systems in the lower part of the Yingshan Formation. Conversely, a large amount of hypogenic karst systems are developed along the SN4 fault zone in the upper part of the Yingshan Formation, located at the top of the secondary faults (Figures 4(d), 4(e), and 4(f)). Therefore, preexisting epigenic karst systems and faults influenced the distributions of hypogenic karst systems, which were also utilized to interpret the reason why hypogenic karst systems focused distributing along the faults in the upper part of the Yingshan Formation. It is explained further below.

7.1.1. Faults. There are four periods of tectonic activities in the Shunnan area of the Tarim Basin: the Early and Middle Caledonian phases, the Late Caledonian to the Early Hercynian phases, and the Late Hercynian phases. The tectonic stress intensity developed moderately during the Early Caledonian phases and then subsequently increased during the MiddleLate Caledonian to the Early Hercynian phases, after which the strength gradually weakened during the Late Hercynian stage.

The structural fractures of compressional torsional strikeslip faults are wider and easily developed in comparison to transtensional strike-slip faults, which depend on the properties of strike-slip faults and petrophysical characteristics of carbonate rocks [49]. Two major strike-slip fault systems trending NE and NNE are present in the Shunnan area under control of the compressional torsional strike-slip fault tectonic activity of Episode I of the mid-Caledonian. Because the intensity of the NNE strike-slip fault activity is comparatively weak, the fracture scale is smaller and it does not have hereditability in the late period. Conversely, the NE strike-slip fault cuts through multiple layers and reaches the Sinian system. Hydrothermal fluids below the basement migrate upwards along the strike-slip fault and react with the Ordovician carbonate strata $[30,33]$.

The SN4 fault system is a typical instance of the northeastsouthwest-trending strike-slip faults systems, and the structure style of which was strongly influenced by the transtensional tectonic stress from the Late Caledonian to early Hercynian. The positive flower structure occurred as tectonic inversion, finally forming a series of tensile normal faults. The tensile normal faults are good vertical migration pathways, which provide favorable conditions for the hydrothermal fluids to migrate upward. In addition, the vertical conduction through faults is superior to the lateral conduction through the effective carbonate reservoir, so fluids will choose effective and opened faults while migrating upward; thus, hypogenic karst systems are developed around and at the end of opened faults (Figures 4(d), 4(e), and 4(f)), showing a belt-shaped distribution along the SN4 fault belt (Figure 4(c)).
7.1.2. Epigenic Karst Systems. Epigenic karst systems are developed in the lower part of the Yingshan Formation, because the Shunnan area was subjected to intensive dissolution as a result of long-term exposure as sea level descends though with no strong tectonic uplift activities this time. On the contrary, epigenic karst systems are comparatively less developed in the upper part of the Yingshan Formation without exposure condition, because the area was under control of the tectonic activity of Episode I in mid-Caledonian and located at downthrown side of fault, resulting in no exposure at surface after the deposition of Yingshan and Yijianfang Formations.

However, recent interpretations considered the importance of preexisting epigenic karst systems, as effective permeability formations [33]. They provide conductive conditions for the lateral dissolution and are beneficial for the formation of lateral stratiform hypogenic karst systems. Hydrothermal fluids from the deep migrate to the top of secondary faults and then along preferential permeability formation to migrate laterally, making it possible for stringbeads-like individuals of the scattered epigenic karst systems to communicate with each other and become string-beadslikes complexes of a massive hypogenic karst systems.

7.2. Relationships between Sequence Boundaries and Preexisting Epigenic Karst Systems. Based on the principles of sequence stratigraphy and taking into account the empirically derived base level, volumetric partitioning, and facies variations, we proposed sequence stratigraphic framework for the Yingshan Formation. It includes two third-order sequences, namely, SQ2 and SQ3 from bottom to top (Figure 7). Sequences SQ2 and SQ3 correspond to the lower and upper parts of the Yingshan Formation, respectively.

Karst systems of the Yingshan Formation were meticulously identified, calibrated, and correlated by well log data combined with previous studies $[40,50]$. The results speculated that two different types of the karst system are present in the sequences SQ2 and SQ3, respectively.

Sequence SQ2 is predominantly characterized by individual string-beads-like seismic reflection (Figure 7). The distributions of epigenic karst systems and sequence boundaries are related, showing the developments of epigenic karst systems correspondingly migrated to top from bottom of the sequence boundary from highlands to lowlands (Figure 7). The reason is that highlands experienced long-term intensive erosion and surface denudation than that of lowlands as the sea level falls geomorphically, causing wide ranges of epigenic karst systems developed close to the bottom of the sequence boundary.

Sequence SQ3 is predominantly characterized by complex string-beads-like seismic reflections (Figures 4(c), 4(d), $4(\mathrm{e})$, and $4(\mathrm{f}))$. The carbonate platforms began to enter the burial stage after experiencing multiple tectonic subsidence. Faults caused by the tectonic activities provide the potential pathways for the hydrothermal fluids to migrate upwards. Thus, deep hydrothermal fluids entered the overlying carbonate strata near the fault and dissolved soluble layers, producing the formation of hypogenic karst systems. 


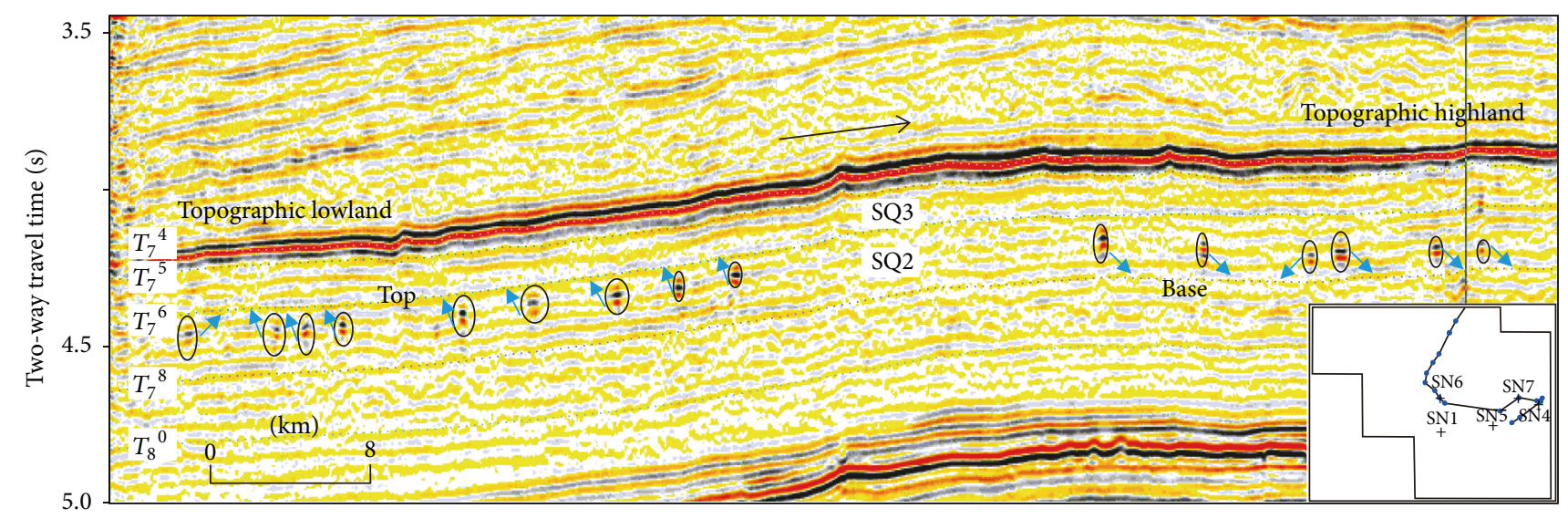

FIGURE 7: Seismic dip section showing individual string-beads-like seismic reflections of epigenic karst systems in the lower part of the Yingshan Formation, which developed near the base and top of sequence boundary in the topographic highland and lowland, respectively.

7.3. Relationships between Geomorphology and Hypogenic Karst System. Paleogeomorphology is a comprehensive response of what a study area has experienced, including structural deformation, depositional infilling, differential compaction, weathering, and erosion (e.g., [37]). Previous studies and exploration efforts have confirmed that paleogeomorphology is one of the key controlling factors for the development of epigenic karst (e.g., [51]), also applicable in Shunnan area.

The Shunnan area is dominated by platform facies deposits during Middle-Lower Ordovician, which were denuded to different degrees in different zones under control of multiphased Caledonian-Hercynian tectonic uplift. To better understand the relationship between seismic geomorphology and the distribution of hypogenic karst systems in this area, the paper is based primarily on interpretations of an integrated data set, including 3D seismic data and well data. The paleogeomorphology in the upper part of the Yingshan Formation was reconstructed, including topographic features of low uplifts, gentle slopes, and sags of the intraplatform (Figure 8). The paleogeomorphology framework is marked by widely distributed sags northwest and comparatively developed low uplifts southeast, whereas gentle slopes are overall less developed (Figure 8).

In addition, the paleogeomorphological map shows that hypogenic karst systems in the upper part of the Yingshan Formation are widely distributed along the faults, which are located in the low uplifts of the intraplatform. The reason why hypogenic karst systems are easily distributed in the highlands is that geomorphically highlands of the intraplatform are easier places to develop a lot of dissolved pores with good connectivity, which are characterized by the well development of vadose zones. Furthermore, the dissolved pores with good connectivity not only provide much reservoir space for the original dense carbonate but also superimpose faults to provide upward pathways for the fluids migration. These factors contribute to the epigenic karst systems development and preexisting epigenic karst systems in the lower part of the Yingshan Formation were a precursor for subsequent hypogene karstification.

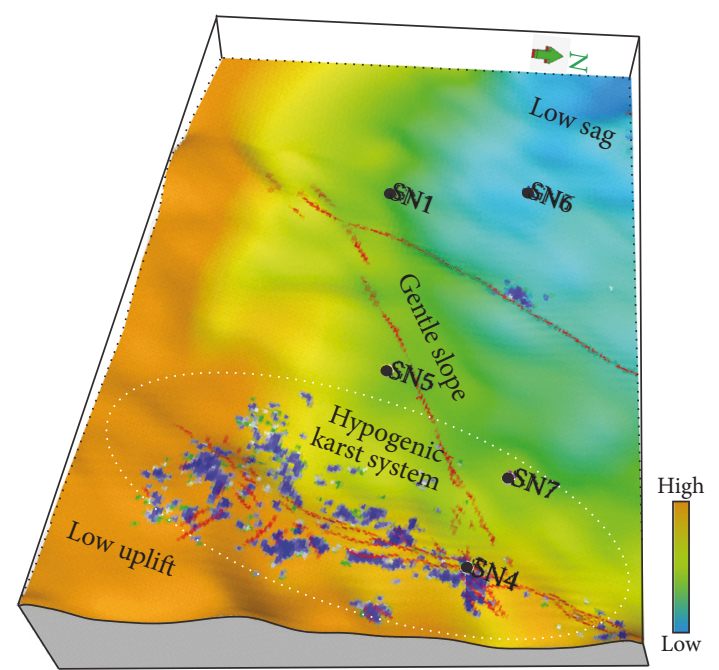

FIGURE 8: Relationships of paleogeomorphology and hypogenic karst systems of the upper part of the Yingshan Formation, showing belt-shaped distributions at the highlands of the margin of intraplatform along the SN4 fault zone.

7.4. Relationships between Sedimentary Facies and Hypogenic Karst Systems. The Middle-Lower Ordovician Penglaiba and Yingshan Formations are mainly a set of marine carbonate platform facies deposits, and they are also a typical restrictedopen sedimentary sequence platform of transgression type. A dolomitic to limestone lithological trend exists from the Penglaiba to Yingshan Formation, primarily showing the variations from pure dolomite, gray dolomite, and dolomitic limestone in the Penglaiba Formation to the granular and micrite limestone in the Yingshan Formation (e.g., [52-54]).

During the deposition of the Penglaiba Formation, the restricted platform facies are primarily composed of microcrystalline argillaceous dolomite and dolomudstone. It corresponds to a deposit formed in a restricted (partially closed) environment, probably, associated with poor water circulation caused by the sea-floor topography barrier. In contrast, 


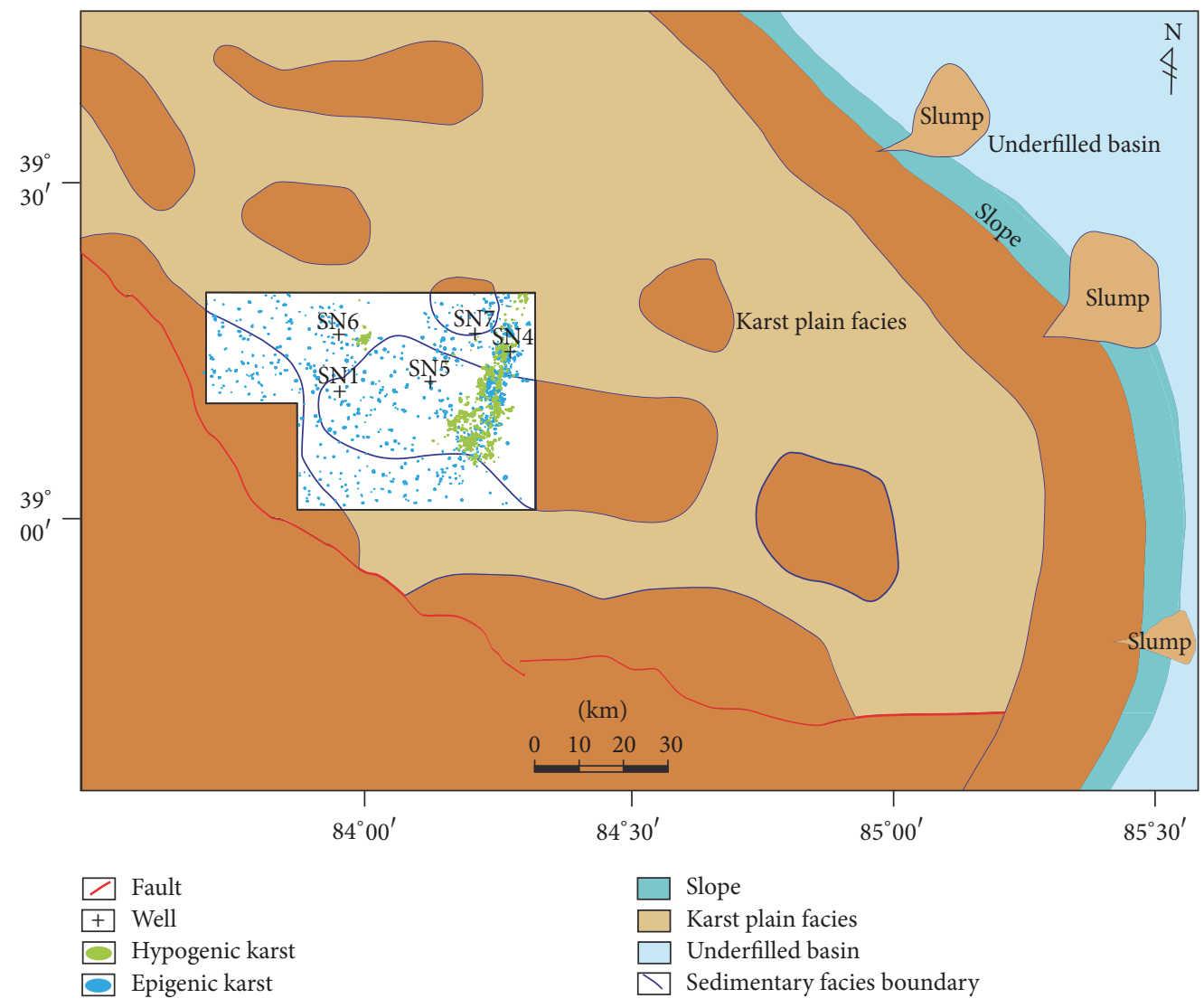

FIGURE 9: Relationships of the sedimentary facies and hypogenic karst systems of the upper and lower part of the Yingshan Formation, showing well coupling between the distribution of intraplatform shoals and the development of hypogenic karst systems.

with the ascent of sea level, a small amount of limestone occurs as thin layer and intercalated in the dolomite during the deposition of the Yingshan Formation, indicating smooth water circulation.

More previous studies revealed that a large number of intraplatform shoals deposited in the Yingshan Formation [55-57]. Sparry calcarenite is the main lithology of the intraplatform shola facies in the Tazhong area [58]. The lithology gradually varies from the sparry calcarenite to micrite away from the intraplatform shola facies. Compared with the micrite, original porosities of sparry calcarenite are easily developed and more easily dissolved by the meteoric or hightemperature fluids, and thus karst systems (epigenic karst and hypogenic karst) are easily developed in the area of the intraplatform sholas. In the study area, Figure 9 also shows the close relationships between the intraplatform shoals and the karst systems (epigenic and hypogenic karst systems). Intraplatform shoals are generally developed in geomorphically highlands of the local super-shallow water.

\section{Conclusions}

This study documented the presence of hypogenic karst systems (lateral stratiform hypogenic and cross-formational fault-vein hypogenic karst system) characterized by complex string-beads-like seismic reflections in a data set from the
Tarim Basin. The features are clustered near known faults in the data set, and this, coupled with a new workflow using seismic amplitude thresholding, fault interpretation, pickup, and merge display to characterize the coupling relationship between them, leads us to propose the development pattern of hypogenic karst systems. Fluids expelled from the deep subsurface move upwards along the vertical pathways (multilevel faults), creating an aggressive fluid that is transported to horizontally lateral carrier-beds, further forming selective dissolution. The accumulations of fluids at the top of the secondary faults make it possible for the formation of a massive hypogenic karst system of string-beads complexes with such features as dendritic distribution, layered distribution, and interfingered bead strings.

Potential controlling factors that influenced the development of hypogenic karst systems have been illustrated by a variety of end-member attributes that are distinct in terms of faults, sequence boundaries, preexisting epigenic karst systems, paleogeomorphology, and sedimentary facies. The hypogenic karst systems are not evenly distributed across the study area but are most common in the highlands along the faults, where epigenic karst systems are usually developed because the residual space of an epigenic karst system is conducive to the convergence of hydrothermal fluids. Trapped hydrothermal fluids from the deep scattered epigenic karst systems communicate with one another and form 
massive hypogenic karst systems. In addition, karst systems develop in association with both the sequence boundaries and sedimentary facies. The development of epigenic karst systems migrates to the top from the bottom of the sequence boundary from the highlands to lowlands. It also has a close relationship with the presence of intraplatform shoals.

\section{Conflicts of Interest}

The authors declare that they have no conflicts of interest.

\section{Acknowledgments}

This research is sponsored by the National 973 research program on "Tectonic evolution and the differences of hydrocarbon accumulation process of the Upper Paleozoic in the Tarim Basin” (no. 2012CB214804).

\section{References}

[1] S. Bloch, R. H. Lander, and L. Bonnell, "Anomalously high porosity and permeability in deeply buried sandstone reservoirs: origin and predictability," AAPG Bulletin, vol. 86, no. 2 , pp. 301-328, 2002.

[2] J. M. Ajdukiewicz, P. H. Nicholson, and W. L. Esch, "Prediction of deep reservoir quality using early diagenetic process models in the jurassic norphlet formation, gulf of Mexico," AAPG Bulletin, vol. 94, no. 8, pp. 1189-1227, 2010.

[3] X. Pu, L. Zhou, W. Wang et al., "Medium-deep clastic reservoirs in the slope area of Qikou sag, Huanghua depression, Bohai Bay Basin," Petroleum Exploration and Development, vol. 40, no. 1, pp. 38-51, 2013.

[4] S. J. Mazzullo and P. M. Harris, "Mesogenetic dissolution: its role in porosity development in carbonate reservoirs," AAPG Bulletin, vol. 76, no. 5, pp. 607-620, 1992.

[5] A. N. Palmer, "Geochemical models for the origin of macroscopic solution porosity in carbonate rocks," in Unconformities and Porosity in Carbonate Strata, A. D. Budd, A. H. Saller, and P. M. Harris, Eds., vol. 63 of AAPG Memoir, pp. 77-101, 1995.

[6] A. Klimchouk, "Speleogenesis, hypogenic," in Encyclopedia of Caves, D. C. Culver and W. B. White, Eds., pp. 748-765, Elsevier, Academic Press, Chennai, India, 2nd edition, 2012.

[7] A. Klimchouk, "The karst paradigm: changes, trends and perspectives," Acta Carsologica, vol. 44, no. 3, pp. 289-313, 2015.

[8] D. C. Ford and P. W. Williams, Karst Geomorphology and Hydrology, Unwin Hyman, London, UK, 1989.

[9] D. Ford and P. Williams, Karst Hydrogeology and Geomorphology, Wiley, Chichester, UK, 2007.

[10] A. N. Palmer, "Origin and morphology of limestone caves," Geological Society of America Bulletin, vol. 103, no. 1, pp. 1-21, 1991.

[11] A. N. Palmer, "Distinction between epigenic and hypogenic maze caves," Geomorphology, vol. 134, no. 1-2, pp. 9-22, 2011.

[12] H. Hu, Z. Y. Wang, and Y. F. Zhang, "The characteristics of the interbedding weathering crust karst in the Yingshan Formation, North slope of the Tazhong Uplift," Xinjiang Petroleum Geology, vol. 34, no. 1, pp. 277-281, 2013.

[13] F. Renwei, O. Cheng, P. Yanjun et al., "Evolution modes of interbedded weathering crust karst: a case study of the $1^{\text {st }}$ and $2^{\text {nd }}$ members of Ordovician Yingshan Formation in EPCC block, Tazhong, Tarim Basin," Petroleum Exploration and Development, vol. 41, no. 1, pp. 49-59, 2014.

[14] Z. M. Wang, L. J. Zhang, and C. H. Sun, "Classification period and exploration for carbonate karst in the Ordovician, Tarim Basin," Journal of Palaeogeography, vol. 17, pp. 635-644, 2015.

[15] A. B. Klimchouk, Hypogene Speleogenesis: Hydrogeological and Morphogenetic Perspective, vol. 36 of Special Paper No. 1, National Cave and Karst Research Institute, Carlsbad, New Mexico, 2007.

[16] K. W. Stafford, L. Land, and A. Klimchouk, "Hypogenic speleogenesis within seven rivers evaporites: coffee cave, eddy county, New Mexico," Journal of Cave and Karst Studies, vol. 70, no. 1, pp. 47-61, 2008.

[17] K. Stafford, L. Land, and G. Veni, Advances in Hypogene Karst Studies, National Cave and Karst Research Institute, Carlsbad, Calif, USA, 2009.

[18] A. B. Klimchouk and D. C. Ford, Hypogene Speleogenesis and Karst Hydrogeology of Artesian Basins, Ukrainian Institute of Speleology and Karstology, Simferopol, Crimean, 2009.

[19] T. Chavez and P. Reehling, "Proceedings of Deep Karst: Origins, Resources, and Management of Hypogene Karst. National Cave and Karst Research Institute, Carlsbad," 2016.

[20] Z. Q. Gao, T. L. Fan, Z. F. Jiao, and Y. Li, "The structural types and depositional characteristics of carbonate platform in the cambrian-ordovician of tarim basin," Acta Sedimentologica Sinica, vol. 24, no. 1, pp. 19-27, 2006.

[21] T. L. Fan, B. S. Yu, and Z. Q. Gao, "Characteristics of carbonate sequence stratigraphy and its control on oil-gas in Tarim Basin," Geoscience, vol. 21, pp. 57-65, 2007.

[22] A. J. Shen, W. Q. Pan, X. P. Zheng, L. J. Zhang, Z. F. Qiao, and N. Y. Mo, "Types and characteristics of Lower Paleozoic karst reservoirs in Tarim Basin," Marine Origin Petroleum Geology, vol. 15, pp. 20-29, 2010.

[23] H. Zeng, R. Loucks, X. Janson et al., “Three-dimensional seismic geomorphology and analysis of the Ordovician paleokarst drainage system in the central Tabei Uplift, northern Tarim Basin, western China," AAPG Bulletin, vol. 95, no. 12, pp. 20612083, 2011.

[24] H. Zeng, G. Wang, X. Janson et al., "Characterizing seismic bright spots in deeply buried, Ordovician Paleokarst strata, Central Tabei uplift, Tarim Basin, Western China," Geophysics, vol. 76, no. 4, pp. B127-B137, 2011.

[25] L. Yun and Z. Cao, "Hydrocarbon enrichment pattern and exploration potential of the Ordovician in Shunnan area, Tarim Basin," Oil and Gas Geology, vol. 35, no. 6, pp. 788-797, 2014.

[26] G. Zhiqian, L. Zhongbao, G. Shanlin, D. Qunan, W. shiqiang, and L. Shilin, "Characteristics and genetic models of Lower Ordovician carbonate reservoirs in southwest Tarim Basin, NW China," Journal of Petroleum Science and Engineering, vol. 144, pp. 99-112, 2016.

[27] C. Z. Jia, Structural Characteristics and Oil \& Gas in the Tarim Basin, Petroleum Industry Press, Beijing, China, 1997.

[28] D. F. He, X. Y. Zhou, C. J. Zhang, W. J. Yang, and X. Shi, "Characteristics of geologic framework of multicycle superimposed basin in Tarim basin," China Petroleum Exploration, vol. 11, no. 1, pp. 31-41, 2006 (Portuguese).

[29] X. Lan, X. Lü, Y. Zhu, and H. Yu, "The geometry and origin of strike-slip faults cutting the Tazhong low rise megaanticline (central uplift, Tarim Basin, China) and their control on hydrocarbon distribution in carbonate reservoirs," Journal of Natural Gas Science and Engineering, vol. 22, pp. 633-645, 2015. 
[30] M. Wu, Y. Wang, M. Zheng, W. Zhang, and C. Liu, “The hydrothermal karstification and its effect on Ordovician carbonate reservoir in Tazhong uplift of Tarim Basin, Northwest China," Science in China, Series D: Earth Sciences, vol. 50, no. 2, pp. 103-113, 2007.

[31] J. W. Hedenquist and R. W. Henley, "The importance of $\mathrm{CO}_{2}$ on freezing point measurements of fluid: evidence from active geothermal systems and implications for epithermal ore deposition," Economic Geology, vol. 80, no. 5, pp. 1379-1406, 1985.

[32] M. Jébrak, "Hydrothermal breccias in vein-type ore deposits: a review of mechanisms, morphology and size distribution," Ore Geology Reviews, vol. 12, no. 3, pp. 111-134, 1997.

[33] P. J. Li, H. H. Chen, D. Q. Tang et al., "Coupling relationship between ne strike-slip faults and hypogenic karstification in middle-lower ordovician of Shunnan Area, Tarim Basin, Northwest China," Earth Science, vol. 42, no. 1, pp. 93-104, 2017.

[34] H. L. Li, N. S. Qiu, Z. J. Jin, and Z. L. He, "Geothermal history of Tarim basin,” Oil and Gas Geology, vol. 26, no. 5, pp. 613-617, 2005.

[35] D. Y. Zhu, Q. Q. Meng, W. X. Hu, and Z. J. Jin, "Differences between fluid activities in the Central and North Tarim Basin," Geochimica, vol. 42, no. 1, pp. 82-94, 2013.

[36] R. M. Mitchum, P. R. Vail, and J. B. Sangree, "Seismic stratigraphy and global changes of sea level, Part 6: stratigraphic interpretation of seismic reflection patterns in depositional sequences," AAPG Memoir, vol. 62, pp. 117-134, 1977.

[37] H. Zhu, X. Yang, X. Zhou, and K. Liu, “Three-dimensional facies architecture analysis using sequence stratigraphy and seismic sedimentology: example from the paleogene dongying formation in the bz3-1 block of the bozhong sag, Bohai Bay Basin, China," Marine and Petroleum Geology, vol. 51, pp. 2033, 2014.

[38] C. M. Burberry, C. A. Jackson, and S. R. Chandler, "Seismic reflection imaging of karst in the Persian Gulf: Implications for the characterization of carbonate reservoirs," AAPG Bulletin, vol. 100, no. 10, pp. 1561-1584, 2016.

[39] P. R. Vail, R. M. Mitchum, and R. G. Todd, "Seismic stratigraphy and global changes of sea level," AAPG Memoir, vol. 26, pp. 49212, 1977.

[40] Y. F. Gao, H. Fu, T. Wang, H. F. Yang, and L. X. Zhao, "The features of ordovician sequence boundaries and its controls on carbonate karst in tarim basin," Xinjiang Petroleum Geology, vol. 33, no. 10, pp. 362-367, 2015.

[41] X. Zhu, H. T. Zhu, H. H. Chen, L. Qi, P. J. Li, and L. Yun, "Characterization of hypogenic karst systems in the MiddleLower Ordovician of Shunnan area,Tarim Basin," Oil and Gas Geology, vol. 37, no. 5, pp. 653-662, 2016.

[42] A. McDonnell, R. G. Loucks, and T. Dooley, "Quantifying the origin and geometry of circular sag structures in northern Fort Worth Basin, Texas: paleocave collapse, pull-apart fault systems, or hydrothermal alteration?” AAPG Bulletin, vol. 91, no. 9, pp. 1295-1318, 2007.

[43] G. R. Davies and L. B. Smith Jr., "Structurally controlled hydrothermal dolomite reservoir facies: an overview," $A A P G$ Bulletin, vol. 90, no. 11, pp. 1641-1690, 2006.

[44] P. Eichhubl, N. C. Davatzes, and S. P. Becker, "Structural and diagenetic control of fluid migration and cementation along the Moab fault, Utah," AAPG Bulletin, vol. 93, no. 5, pp. 653-681, 2009.
[45] E. Frankowicz and K. R. McClay, "Extensional fault segmentation and linkages, Bonaparte Basin, outer North West Shelf, Australia," AAPG Bulletin, vol. 94, no. 7, pp. 977-1010, 2010.

[46] H. J. Yang, K. K. Li, W. Q. Pan, Z. Y. Xiao, and C. F. Cai, “Burial hydrothermal dissolution fluid activity and its transforming effect on the reservoirs in Ordovician in Central Tarim," Acta Petrologica Sinica, vol. 28, no. 3, pp. 783-792, 2012.

[47] G. Wu, H. Yang, S. He, S. Cao, X. Liu, and B. Jing, "Effects of structural segmentation and faulting on carbonate reservoir properties: a case study from the Central Uplift of the Tarim Basin, China," Marine and Petroleum Geology, vol. 71, pp. 183197, 2016.

[48] A. Klimchouk, A. S. Auler, F. H. R. Bezerra, C. L. Cazarin, F. Balsamo, and Y. Dublyansky, "Hypogenic origin, geologic controls and functional organization of a giant cave system in Precambrian carbonates, Brazil," Geomorphology, vol. 253, pp. 385-405, 2016.

[49] Q. Miao, M. Pan, H. L. Gao, and B. Zhang, "The 3-D visualization characterization of the complex buried-hill fracture structure," Xinjiang Petroleum Geology, vol. 29, no. 21, pp. 364366, 2008 (Chinese).

[50] W. Q. Pan, Z. M. Wang, C. H. Sun et al., "Classifications of sequence boundaries in the Lower Paleozoic carbonates in Tarim Basin and their significances," Oil and Gas Geology, vol. 32, no. 1, pp. 531-541, 2011.

[51] Z. H. Kang, "The karst paleogeomorphology of carbonate reservoir in Tahe Oilfield," Xinjiang Petroleum Geology, vol. 27, pp. 522-525, 2006.

[52] L. D. Wang, Formation mechanics and distribution forecast of Carbonates Paleokarst reservoir in $T_{7}^{4}$ Interface from Central Tarim Basin [Ph.D. thesis], PhD Dissertation in China University of Geosciences, Beijing, China, 2007.

[53] S. W. Xie, A Study on Sequence Stratigraphy and Geological Characteristics for Yingshan Formation in the Central Uplift Aera of Tarim Basin, China [Ph.D. thesis], PhD Dissertation in Chengdu Univerisity of Technology, 2011.

[54] Z. F. Zhai, A Study on the Sequence stratigraphy and Sedimentary Characteristic of Ordovician in Tazhong area of Tarim basin [Ph.D. thesis], PhD Dissertation in Chengdu Univerisity of Technology, 2012.

[55] W. Liu, X. Y. Zhang, and J. Y. Gu, "Corrosion inhibition and adsorption properties of methocarbamol on mild steel in acidic medium," Portugaliae Electrochimica Acta, vol. 27, no. 1, pp. 435442, 2009.

[56] C. L. Wang, G. H. Wu, W. J. Cui et al., "Characteristics and distribution of intra-platform beach of the lower-middle ordovician yingshan formation carbonate," Acta Sedimentologica Sinica, vol. 29, pp. 1048-1058, 2011.

[57] Z. K. Jin, L. Shi, B. S. Gao, and K. H. Yu, "Carbonate facies and facies models," Acta Sedimentologica Sinica, vol. 31, no. 1, pp. 965-980, 2013.

[58] J. H. Zhang, B. S. Yu, Z. L. Qi, Z. K. Bai, Z. Ruan, and L. R. $\mathrm{Li}$, "Seismic facies and the distribution of the intraplatform sholas in the Ordovician Yingshan Formation in the Ka-1 three-dimensional seismic area, Central Tarim Basin, Xinjiang," Sedimentary Geology and Tethyan Geology, vol. 36, no. 3, pp. 104-112, 2016. 

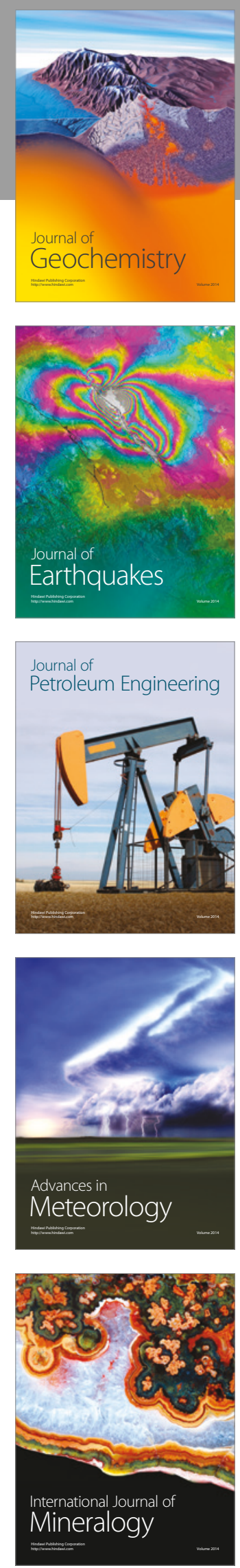
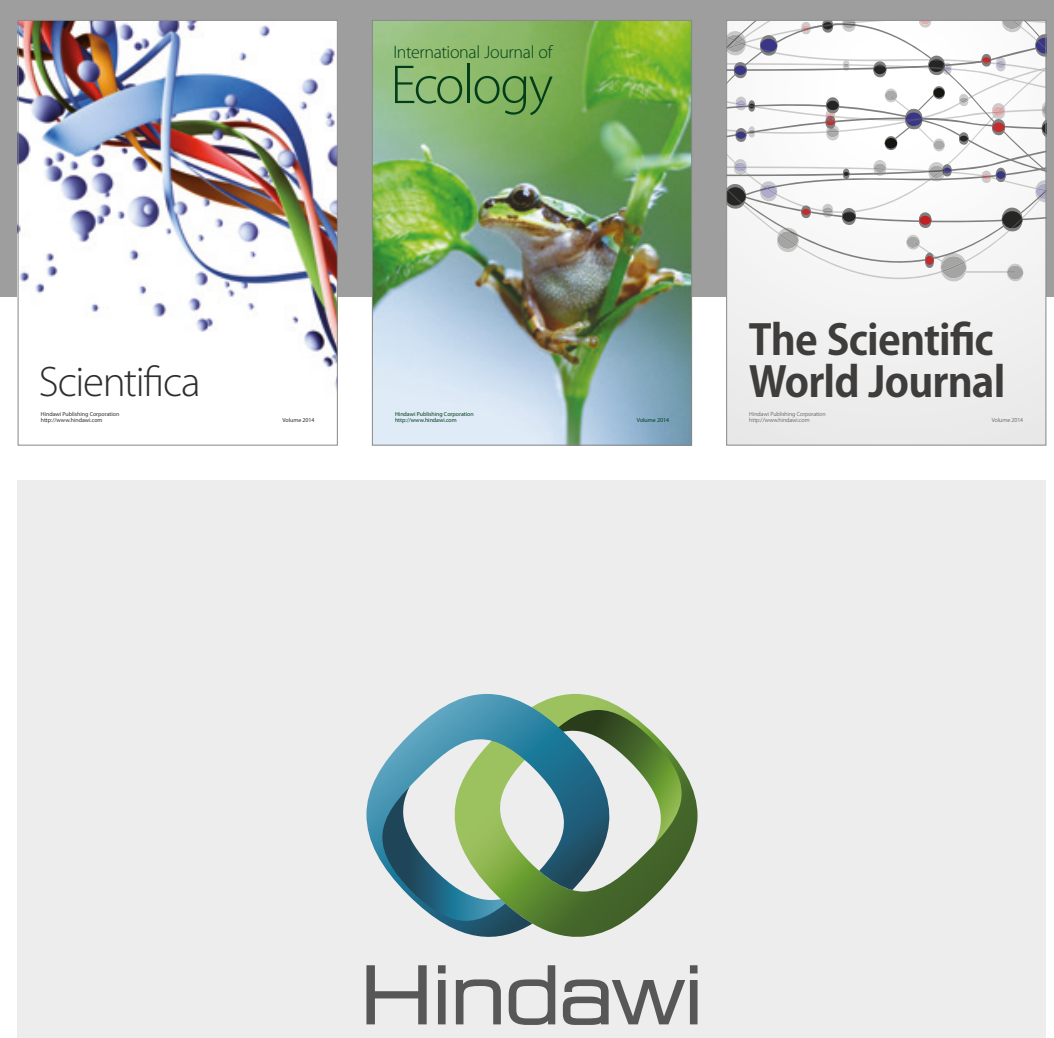

Submit your manuscripts at

https://www.hindawi.com
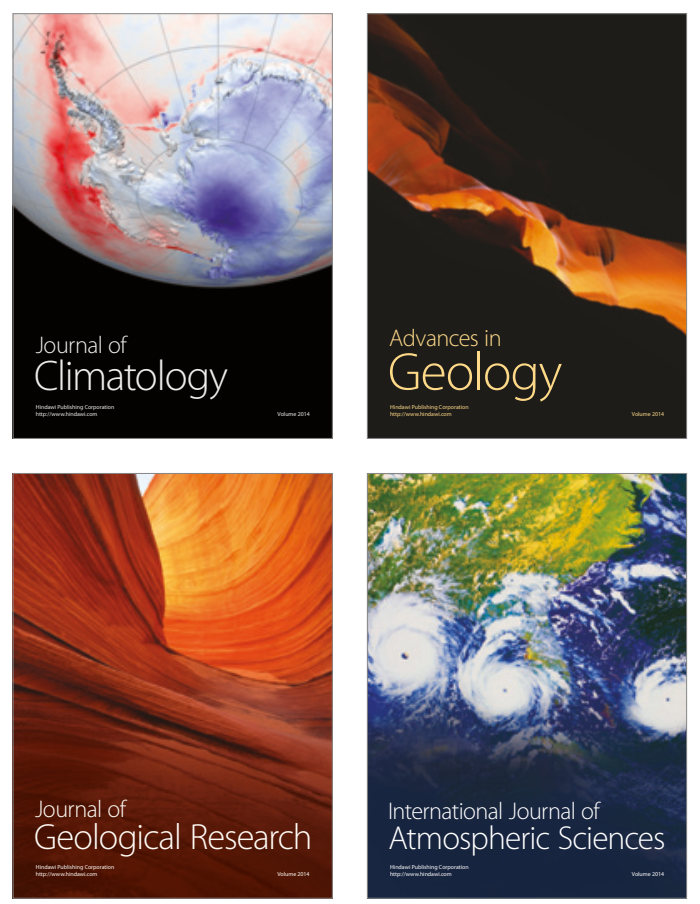

The Scientific

World Journal
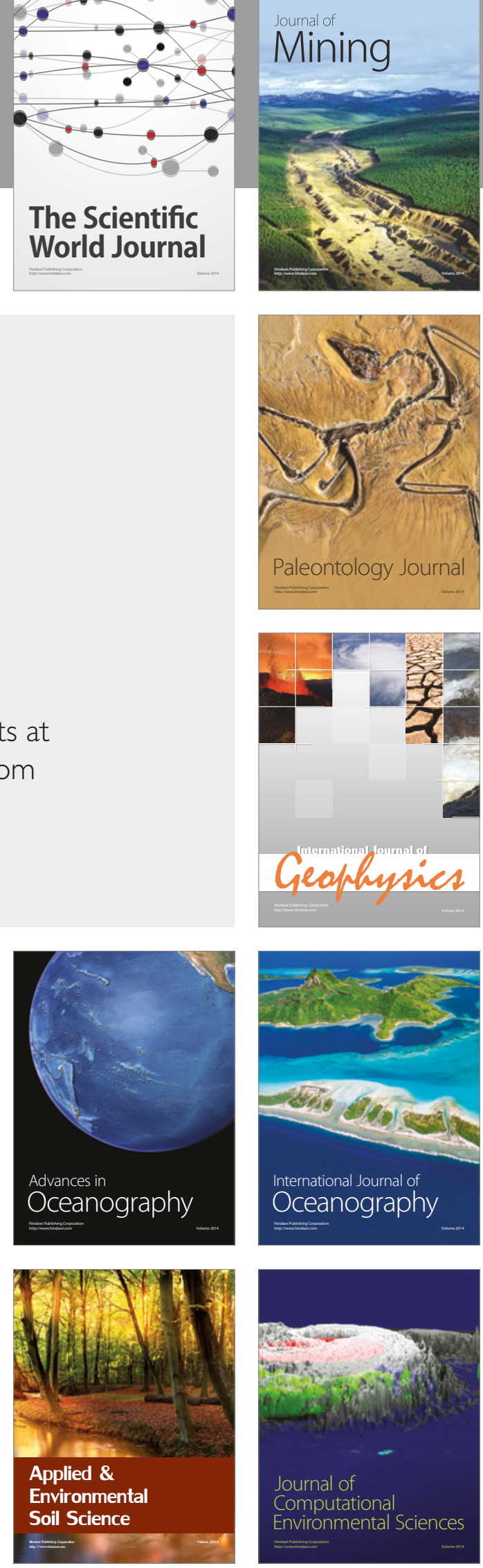